\title{
Lenvatinib for the treatment of renal cell carcinoma
}

\section{Giandomenico Roviello, Silvia Paola Corona, Giovanni Bozza, Michele Aieta, Daniele Generali, Maria Grazia Rodriquenz, Anna Maria Mileo, Marco Imperatori, Anna Ianza, Raffaele Conca \& Navid Sobhani}

To cite this article: Giandomenico Roviello, Silvia Paola Corona, Giovanni Bozza, Michele Aieta, Daniele Generali, Maria Grazia Rodriquenz, Anna Maria Mileo, Marco Imperatori, Anna lanza, Raffaele Conca \& Navid Sobhani (2018): Lenvatinib for the treatment of renal cell carcinoma, Expert Opinion on Investigational Drugs, DOI: 10.1080/13543784.2018.1472235

To link to this article: https://doi.org/10.1080/13543784.2018.1472235

Accepted author version posted online: 02

May 2018.

Submit your article to this journal $₫$

Q View related articles $₫$

View Crossmark data \lceil 


\section{Lenvatinib for the treatment of renal cell carcinoma}

Running title: Lenvatinib for RCC.

Giandomenico Roviello ${ }^{1}$, Silvia Paola Corona ${ }^{2}$, Giovanni Bozza ${ }^{1}$, Michele Aieta ${ }^{1}$, Daniele

Generali $^{3,4}$, Maria Grazia Rodriquenz ${ }^{1}$, Anna Maria Mileo ${ }^{1}$, Marco Imperatori ${ }^{1}$, Anna $\operatorname{Ianza}^{3}$, Raffaele Conca $^{1}$, Navid Sobhani ${ }^{3}$

1. Division of Medical Oncology, Department of Onco-Hematology, IRCCS-CROB, Referral Cancer Center of Basilicata, via Padre Pio 1, 85028 Rionero, Vulture (PZ), Italy

2. Peter MacCallum Cancer Centre - Moorabbin Campus, 865 Centre Road, Bentleigh East 3165, Melbourne Vic, Australia

3. Department of Medical, Surgery and Health Sciences, University of Trieste, Piazza Ospitale 1, 34129 Trieste, Italy

4. Breast Cancer and Translational Research Unit, ASST Cremona, Viale Concordia 1, 26100 Cremona, Italy

\section{Address for correspondence:}

Giandomenico Roviello MD

Division of Medical Oncology, Department of Onco-Hematology, IRCCS-CROB, Referral Cancer Center of Basilicata, via Padre Pio 1, 85028 Rionero, Vulture (PZ), Italy

E-mail: giandomenicoroviello@hotmail.it

Keywords: Renal cell carcinoma, Lenvatinib, VEGFR1-3, RET, FGFR1-4, PDGFR $\alpha$, c-KIT 


\section{Abstract}

Introduction: Renal cell carcinoma (RCC) accounts for 2-3\% of all solid tumors. Expression of the receptor for the Vascular Endothelial Growth Factor (VEGF) is one of the most common features of RCC.

Areas Covered: Lenvatinib is a novel multi-kinase inhibitor that has been studied in several solid tumors. It has shown promising results in the treatment of RCC, especially when combined with everolimus, In this review, we summarize the available data of lenvatinib for the treatment of advanced/metastatic renal cell carcinoma.

Expert Opinion: Lenvatinib in combination with everolimus has provided encouraging results in both clinical and laboratory investigations showing that blocking angiogenesis and the mTOR signalling pathway could be a remarkable approach for treating RCC. As an additive to this type of approach it would be interesting in future clinical settings testing also the combination of lenvatinib and everolimus with immune-therapy.

\subsection{Introduction}


Kidney cancer is the eight most common cancer-related cause of death in the world, with just in the USA an estimated 63,340 new diagnoses and 14,970 deaths in $2018^{1}$. The incidence of the disease is expected to increase by about $2 \%$ this year compared to last year ${ }^{1,2}$.

Renal cell carcinoma (RCC) originates in the renal cortex and it is responsible for approximately $90 \%$ of all primary renal neoplasms, with a prevalence twice as high in men compared to women. Although different drugs are currently available for RCC, the prognosis of the metastatic stage of disease still remains poor ${ }^{3-5}$.

While conventional chemotherapy for RCC reported relatively poor outcomes, some innovative and biological drugs have been implemented for the treatment of RCC patients in the past ten years. Such treatments, including small tyrosine kinase inhibitors of the Vascular Endotelial Growth Factor Receptor (VEGFR) mTOR inhibitors and checkpoint inhibitors. In particular, after sunitinib, the Food and drug administration (FDA) approved other antiangiogenic drugs such as sorafenib, pazopanib, axitinib, and bevacizumab. Furthermore, the FDA approved mTOR inhibitors temsirolimus and everolimus and recently, the only two agents able to improve survival, cabozantinib and nivolumab ${ }^{5}$.

In this context, lenvatinib, a novel tyrosine kinase inhibitor selectively targeting VEGFR-1, VEGFR-2, VEGFR-3, fibroblast growth factor receptors (FGFR1, FGFR2, FGFR3 and FGFR4), platelet-derived growth factor receptor (PDGFR $\alpha$ ), proto-oncogenes RET and c-KIT ${ }^{6-8}$.

Motzer RJ et al. showed increased Progression Free Survival (PFS) and Overall Survival (OS) with the combination of lenvatinib plus everolimus in comparison to everolimus alone in a multi-centred randomized-to-control phase II study of $\mathrm{RCC}^{9}$. The aim of this mini-review is to summarize the first preliminary and clinically available data on lenvatinib in advanced/metastatic RCC. Finally, future directions will be discussed.

\section{The molecular bases of tumor angiogenesis}


It was not until relatively recent times that sporadic and hereditary mutations in the Von-HippelLindau (VHL) gene were proven responsible for the development of RCC. The VHL gene was found on the human chromosome $3 \mathrm{p} 25.5$ for the first time in $1993^{10}$ as a tumor suppressor gene. Other than being implicated in the inherited von Hippel-Lindau disease, mutations of this gene are also found implicated in sporadic RCC. Mutations of the VHL gene have been associated with the majority of cases of sporadic RCC11. After these first discoveries, the pathway was considered as a potential candidate for targeted therapy of this disease. One of the most well-known targets of VHL gene is the hypoxia-inducible factor $\alpha$ (HIF- $\alpha$ ), a transcription factor involved in the regulation of various angiogenic factors. In fact, in the absence of oxygen, HIF- $\alpha$ interacts with its heterodimer hypoxia-inducible $\beta$ (HIF- $\beta$ ) to form a complex that leads to the transcription of hypoxia-inducible genes such as vascular endothelial growth factor (VEGF), platelet-derived growth factor $\beta$ (PDGF$\beta$ ), transforming growth factor $\alpha(\mathrm{TGF}-\alpha)$ and erythropoietin (EPO). In the presence of oxygen, however, the pVHL binds and hydroxylases two proline residues of HIF- $\alpha$ leading to its ubiquitination and subsequent degradation by proteasomes ${ }^{10}$. The presence of VHL gene mutations leads to inactivation of this oxygen-dependent degradation of HIF- $\alpha$ with an up-regulation of angiogenic factors.

In physiological conditions, and especially during early stages of life, angiogenesis is an important process by which new blood vessels are formed in order to deliver required oxygen and nutrients to peripheral tissues, maintaining the required levels of perfusion. Considered nowadays as a universal cancer hallmark, neo-angiogenesis in the context of a tumour provides new blood vessels that will ultimately result in enhanced tumor growth and increased metastatic potential. One of the most common features of cancer neo-angiogenesis is that it is highly regulated. It is mainly based on the interactions between tissue soluble VEGFs ligands and VEGFRs. These interactions work perfectly in healthy conditions, while they become deleterious during tumourigenesis and cancer progression. Sub-variants of VEGF molecules in humans are VEGF-A, VEGF-B, VEGF-C, VEGF-D and placental growth factor $(\mathrm{PlGF})^{12,13}$. The VEGF receptor family consists of three molecular subtypes 
(VEGFR-1, VEGFR-2 and VEGFR-3), which are type-II transmembrane tyrosine kinase (TK) proteins $^{12}$. Among these receptor subtypes, the main one associated with the pathological formation of blood vessels in the context of solid tumors is VEGR-2 (Figure 1).

VEGFR-2 is usually expressed on the surface of vascular endothelial cells and circulating bone marrow-derived endothelial progenitor cells ${ }^{13}$. Upon binding of VEGF molecules to VEGFR-2, the receptor dimerizes and auto-phosphorylates at the carboxyl-terminal TK domain leading to activation of the signaling transduction pathway downstream. Consequently, various specific molecular pathways are activated at the same time (Figure 1): the PLC $\gamma /$ PKC/MAPK pathway, related to endothelial cells migration; the PI3K/AKT/mTOR pathway, whose activation leads to increased survival of endothelial cells and increased vascular permeability; the Raf/MEK/Erk pathway, which promotes endothelial cells proliferation ${ }^{14,15}$. The VEGFR-2 has a significantly more robust kinase activity than VEGFR-1 even if the binding between VEGF-A and VEGFR-2 (KDR Flk-1 in mice) occurs with an affinity one order lower than that of VEGFR-1 (Flt-1 in mice) $(\mathrm{Kd}=$ $1-10 \mathrm{pM})^{14}$. The activation of the VEGFR-2 kinase activity results in a dramatic increase of blood vessels' formation, translating in an increased micro-vessel density and enhanced proliferation rate of vascular endothelial cells ${ }^{13}$. A larger study, enrolling 1091 RCC patients, showed that $79.6 \%$ of patients were positive for VEGF, $62.4 \%$ were positive for VEGFR2, 45\% were positive for PDGFB and $42.5 \%$ were positive for PDGFR- $\beta^{16}$. On the basis of these data, VEGFR-2 is considered a key player in the process of tumor neo-angiogenesis in solid tumors and RCC. As a consequence, VEGFR-2 represents an attractive target for the development of novel anti-cancer therapies.

Sub-variants of fibroblast growth factor (FGF) molecules in humans are FGF1-10. The receptor family consists of four molecular subtypes (FGR-1, FGR-2, FGR-3 and FGR-4), which are highly conserved TK receptors. There are differences among subtypes in their ligand affinities and distribution across tissues ${ }^{17-19}$. Among the FGFR receptor-family, the most commonly amplified was the FGFR1, affected in $3.5 \%$ of the tumours ${ }^{20}$. Moreover, a study looking at 100 primary tumors and 40 metastatic lymph nodes obtained from 140 untreated RCC, showed that FGFR1 and 
FGFR2 were highly expressed in RCC by immunohistochemistry. Expression of FGFR1 was observed in $98 \%(98 / 100)$ of primary tumorous and in $82.5 \%(33 / 40)$ of lymph node metastases. FGFR2 was expressed in 4\% (4/100) of primary tumors and 5\% (2/40) of lymph node metastases. In normal kidneys FGFR1 expression was significantly lower $(p=0.0001)$ than in $\mathrm{RCC}^{21}$.

There is strong evidence pointing out that fibroblast growth factor-2 (FGF2) has an important role in angiogenesis besides the VEGF. As a matter of fact FGF2 is a potent regulator of many cellular functions, such as proliferation, migration, survival, adhesion, motility, apoptosis and physiological functions like wound healing, tumorigenesis, angiogenesis, or blood vessel remodelling or embryonic growth ${ }^{22-24}$.

Other key studied pro-angiogenic factors include TGF- $\beta$ Smad, RAS/RAF1/MEK1-2/ERK1-2, $\mathrm{DAG} / \mathrm{PKC}$ as well as the PI3K/AKT/mTOR and other hypoxia-related genes25,26. These are all factors that increase tumour cell proliferation, growth, survival and angiogenesis.

Therefore, since in RCC there is a high expression of VEGF, VEGFR2, FGFR1, PDGF-B and PDGFR- $\beta$, patients could potentially benefit from a drug that could inhibit multiple tyrosine kinases

\section{Lenvatinib: preclinical and phase I data}

Lenvatinib (4-\{3-chloro-4-[(cyclopropylcarbamoyl)amino]phenoxy\}-7-methoxyquinoline-6carboxamide), is an oral multi-kinase inhibitor capable of selectively inhibit VEGFR1-3 (WO02/32872) and other pro-oncogenic and pro-angiogenic receptor tyrosine kinases, such as FGFR1-4, PDGFR, RET (US9006256) and c-KIT (US7612208B2) ${ }^{6-8}$.

Both in vitro and in vivo analyses were able to prove that lenvatinib plus everolimus were able to enhance anti-tumor activity. Matsuki et al using 3 human RCC xenograft mouse models (A-498, Caki-1 and Caki-2) proved that the combination of lenvatinib and everolimus was able to inhibit to a greater extent the tumor growth in all the three cell lines compared to each single monotherapy, and even tumor regression was observed in two of the xenografted models, A-498 and Caki-1. In these latter two cell lines, the authors pursued an angiogenesis investigation. The A-498 xenografts 
received lenvatinib plus everolimus and the effect of the combination was equivalent to that of lenvatinib monotherapy, suggesting that angiogenesis was primarily suppressed by lenvatinib. A gene array expression by the authors further confirmed the results, showing that angiogenesisrelated genes were down-modulated mainly by the lenvatinib therapy. Moreover, the antiangiogenesis in A-498 xenografts were associated with tissue hypoxia. In Caki-1 cell line xenografted model, tumor microvessel density was significantly reduced by either lenvatinib or everolimus monotherapy. In the 2 cell lines that had tumor regression after receiving the combinatory therapy, the authors pursued also an antiproliferative activity analysis ${ }^{27,28}$. Further evidence by the group proved that lenvatinib with everolimus had a synergistic inhibition of both VEGF and FGF induced proliferation and tube formation in HUVEC cells in vitro. In vivo mice results proved that lenvatinib monotherapy at $7.5 \mathrm{mg} / \mathrm{kg}$ and everolimus monotherapy at $15 \mathrm{mg} / \mathrm{kg}$ significantly inhibited tumor growth vs. controls of both mice models, and that the combination of lenvatinib $(7.5 \mathrm{mg} / \mathrm{kg})$ with everolimus $(15 \mathrm{mg} / \mathrm{kg})$ proved to have a significantly higher anti-tumor activity vs. each of the monotherapies used at the same or even higher doses ${ }^{28}$.

The first clinical evidence showing antitumor activity for lenvatinib in RCC comes from a doseescalating Phase I study (NCT00121719). This trial was designed in such a way that RCC patients received lenvatinib with the defined purpose of determining the maximum tolerated dose (MTD), which was at $25 \mathrm{mg}$ per day. Partial responses (PRs) were observed in $9 \%$ of all the patients and stable disease in 46\%. The median PFS in RCC was of 477 days (95\% CI; 279-559), which was higher than what has been observed of the conventional RCC treatments. Major adverse events were hypertension $(40 \%$; grade $\geq 3: 11 \%)$, diarrhoea $(45 \%)$, proteinuria $(26 \%$; grade $\geq 3 ; 7 \%)$, nausea $(37 \%)$, stomatitis $(32 \%)$ and vomiting $(23 \%)^{29}$.

Subsequently, since everolimus has been already FDA approved for the treatment of RCC in 2015, its combination with lenvatinib represented a valid, rational approach to be tested for the treatment of the disease. The first evidence proving the feasibility of combining lenvatinib plus everolimus in RCC comes from a Phase Ib trial. This trial was made of 20 patients with advanced RCC and it was 
designed with 2 cohorts: in cohort 1, 12mg of lenvatinib and $5 \mathrm{mg}$ of everolimus were administered daily; in cohort 2, subsequently $12 \mathrm{mg}$ of lenvatinib and $5 \mathrm{mg}$ of everolimus were given daily. This trial was designed to determine MTD, which was at $18 \mathrm{mg}$ lenvatinib/5-mg everolimus. The progression rate across patients was of 30\% (95\% CI: $11.9 \%-54.3 \%)$. About $20 \%$ (95\% CI 5.7\%43.7\%) of patients had stable disease after 83 weeks. The median PFS was of 330 days (95\% CI: 157-446; approximately of 10.9 months). The 6- and 12-months PFS were of $72.1 \%$ (95\% CI 48.8$95.4 \%)$ and $49.5 \%$ (95\% CI $22.7-76.2 \%)$, respectively ${ }^{30}$. As to safety concerns, in this phase Ib trial the most frequent adverse events for the combination of the two drugs arm were fatigue $(60 \%$; grade $\geq 3: 10 \%)$, inflammation of the mucosa $(50 \%)$, diarrhea (40\%; grade $\geq 3: 10 \%)$, nausea (40\%), proteinuria (40\%; grade $\geq 3: 15 \%)$, vomiting (40\%; grade $\geq 3: 5 \%)$ and hypertension $(40 \%)$.

\subsection{Phase II and future III trials}

Motzer and colleagues conducted a randomized, phase 2, multi-center clinical trial (NCT01136733) with .purpose of testing whether the combination of lenvatinib plus everolimus was superior in terms of PFS compared to the single agents. For this purpose the authors of the trial designed a randomized, phase 2, open-label, multicenter study at 37 centers in five different countries (UK, Spain, Poland, Czech Republic and the USA). The treatment was administered for 28 day continuous cycles giving to patients lenvatinib $(18 \mathrm{mg} /$ day $)$ as one $10 \mathrm{mg}$ capsule and two $4 \mathrm{mg}$ capsules plus everolimus ( $5 \mathrm{mg}$ /day) as one $5 \mathrm{mg}$ tablet. Patients in the single agent arm with lenvatinib (24 mg/day) were given as two $10 \mathrm{mg}$ capsules and one $4 \mathrm{mg}$ capsule. Patients in the single agent arm with everolimus (10 mg/day) were given two $5 \mathrm{mg}$ tablets. From a total of 153 RCC cases, 50 patients received everolimus as a single drug, 51 received lenvatinib with everolimus, 50 patients received lenvatinib as a single drug. PFS was the primary end-point of the study. The median PFS was higher for the combination of lenvatinib plus everolimus, (PFS of 14.6 months [95\% CI, 5.9-20.1]) compared to the arm of patients treated with everolimus alone (PFS of 5.5 months [3.5-7.1]) (hazard ratio [HR] 0.40, 95\% CI 0.24-0.68; $\mathrm{p}=0.0005$ ). On the other hand, a 
not statistically significant difference was observed for the lenvatinib plus everolimus arm compared to the lenvatinib as single-agent arm (PFS of 7.4 months) (95\% CI 5.6-10.2]; HR 0.66, 95\% CI 0.30-1.10; $\mathrm{p}=0.12$ ). The single-agent lenvatinib arm showed higher PFS compared to single-agent everolimus arm (HR 0.61, 95\% CI 0.38-0.98; $\mathrm{p}=0.048)^{9}$.

The secondary endpoint was Overall Response Rate (ORR), which showed to be significantly higher using the combination of lenvatinib plus everolimus in comparison to single-agent everolimus (43\% vs. 6\%, respectively; PR 7.2; 95\% CI 2.3-22.5; p<0.0001), but not when compared to single agent lenvatinib (43\% vs. 27\%, respectively; PR 1.6; 95\% CI 0.9-2.8; $\mathrm{p}=0.10$ ). Additionally, the ORR difference between single-agent lenvatinib and single agent everolimus was also significantly higher (27\% vs. 6\%, respectively; PR 4.5; 95\% CI 1.4-14.7; $\mathrm{p}=0.0067)^{9}$.

Authors performed also a post-hoc analysis to prove the robustness of the statistical analysis ${ }^{31}$. They used a blinded, independent radiological review (IRR) to assess the efficacy of their results. The primary end point PFS was assessed by IRR in the intention to treat population. The IRR also assessed OS and best objective responses. The primary endpoint was always PFS. In the combination arm PFS was assessed by IRR was 12.8 months (95\% CI 7.4-77.5); in the lenvatinibalone arm PFS was 9.0 months (95\% CI 5.6-10.2) and in the everolimus-alone arm it was 5.6 months (95\% CI 3.6-9.3). PFS was significantly higher in the combination group compared to the everolimus single-agent group (HR 0.45 [95\% CI 0.27-0.79]; $\mathrm{p}=0.0029$ ). Moreover, the post-hoc analysis proved that the OS was of 25.5 months in the lenvatinib plus everolimus arm; 19.7 months the lenvatinib single-agent arm and 15.4 months the everolimus single-agent arm. The comparison between lenvatinib plus everolimus and everolimus alone was statistically significant (HR: 0.51 , 95\% CI $0.30-0.88 ; \mathrm{p}=0.024)$. While the comparison between single-agent lenvatinib and everolimus single-agent was not significant (HR: $0.68 ; 95 \%$ CI $0.41-1.14 ; \mathrm{p}=0.12$ ). Finally, no statistically significant correlation was observed between the combination of lenvatinib plus everolimus and lenvatinib used as single-agent (HR: $0.75,95 \%$ CI $0.43-1.30 ; p=0.32$ ). Therefore, the combination of everolimus with lenvatinib compared to the everolimus single-agent was the unique to show a 
significant OS improvement. As the authors suggested, the differences between this post-hoc analysis and their initial studies was potentially due to the reduced statistical power resulting from the fewer IRR-assessed patients at progression events of the post-hoc analysis ${ }^{31}$. As to safety concerns, the high grade adverse events for the combination of the two drugs arm were d to diarrhea (85\%; grade $\geq 3: 20 \%)$, hypertension $(41 \%$; grade $\geq 3: 14 \%)$ and fatigue $(59 \%$; grade $\geq 3: 14 \%$ ) with the $71 \%$ of patients that required a dose reduction due to adverse events and about one quarter of patients that discontinued the treatment. Interestingly, grade 3-4 adverse events occurred in $71 \%$ of patients receiving lenvatinib+everolimus and in $79 \%$ for single-agent lenvatinib. However, no data on quality of life is available because it was not investigated ${ }^{12}$. However, based on the positive results of the phase II clinical trial, the combination between lenvatinib and everolimus received FDA approval for the treatment of advanced renal cell carcinoma following one prior antiangiogenic therapy.

To date, there are several ongoing clinical trials testing lenvatinib as either first or second line therapy in the treatment of RCC (table 1). A Phase II, randomized, open-label and multicenter clinical trial is looking at lenvatinib in combination with everolimus in the treatment of non clear cell RCC who have not received any therapy for advanced disease. Participants must have one of the following subtypes of nccRCC: papillary, chromophobe, collecting duct carcinoma, renal medullary carcinoma or unclassified (NCT02915783). Another Phase II open label pilot study, aims at primarily measuring ORR in patients treated with the combination of lenvatinib plus everolimus before cytoreductive nephrectomy (NCT03324373). The combination of everolimus and lenvatinib has been also tested in a phase II, randomized, with parallel assignment and triple masking (participant, investigator and outcome assessor) clinical trial aiming to primarily investigate ORR and Treatment Emerged Adverse Events in RCC patients, who previously received one anti-VEGF treatment. The study consists of two arms giving different concentrations of the two drugs: for arm A patients received $18 \mathrm{mg}$ of lenvatinib and $5 \mathrm{mg}$ of everolimus, while for arm B patients received 14 
mg of lenvatinib plus 5mg of everolimus (NCT03173560). Finally, a randomized, multi-centered, parallel assignment, open-label, phase III clinical trial made of 735 patients has been designed in order to test primarily PFS of first line lenvatinib in combination with everolimus (Arm A), or pembrolizumab (Arm B) compared to sunitinib (Arm C) in patients with mRCC. The study also aims to investigate OS and ORR as secondary outcomes (NCT02811861). This trial has been made to compare the efficacy and safety of the combination of these three arms as first-line treatment through the measurement of PFS. As major secondary outcome OS, ORR, AEs will be evaluated.

\section{Expert Opinion}

Lenvatinib in combination with everolimus has provided encouraging results in both clinical and laboratory investigations showing that blocking angiogenesis and the mTOR signalling pathway could be a remarkable approach for treating advanced RCC. Interestingly more clinical trials, including a randomized phase III study, have been directed to investigate this combinatorial treatment in the first line setting. Moreover since RCC is a heterogeneous tumour, it would be interesting to test biomarkers of effectiveness to the treatment with lenvatinib, such as levels of FGFs, FGFR1/2, VEGFs, VEGFR2, PDGF-B and PDFGR- $\beta$. Furthermore, it would be also interesting to test targets of the PI3K pathway for effectiveness to the treatment with everolimus. As an additive to this type of approach future clinical trials will test also the combination of lenvatinib and everolimus with immune-therapy. In fact, preclinical data in vitro have shown that the combination of lenvatinib, used at the therapeutic dose of $0.12 \mathrm{mg}$, with 104 rat uterine cancer adenocarcinoma (RuCa)-sensitized lymphocytes administered continuously in 7-days cycles, the antitumor effect was higher compared to single agents treatments prolonging survival of mice with RCC. Moreover in three cell lines (ACHN, 786-0 and RuCa cells) apoptosis significantly increased when sensitized lymphocytes were added to lenvatinib compared to control $(p<0.01)^{32}$. In addition, mouse models showed that mice inoculated with liver cancer, melanoma or colon cancer cell lines treated with a combination of lenvatinib $(10 \mathrm{mg} / \mathrm{kg}$, once in a day) and anti-mouse PD1 antibody 
( $500 \mathrm{~g} /$ mouse, twice in a week) had a substantial inhibition on tumour growth when compared to individual treatments. Moreover, a greater number of mice demonstrated complete response of tumour in the combination therapy group compared to single treatments ${ }^{32,33}$. Therefore, the combination of agents targeting VEGF and cellular immunotherapy-mediated pathways may block at the same time two critical signaling pathways activated in RCC, overcoming thereby some partial mechanisms crucial for the development of drug resistance in single agent therapy. In an era where immune-therapy is constantly progressing at a high pace, with always newer and more powerful molecules, the combination of lenvatinib with everolimus to some immune-modulation therapy in future randomized clinical trials could be also an interesting approach deserving some clinical validation.

\section{Funding}

This paper was not funded.

\section{Declaration of Interest}

The authors have no relevant affiliations or financial involvement with any organization or entity with a financial interest in or financial conflict with the subject matter or materials discussed in the manuscript. This includes employment, consultancies, honoraria, stock ownership or options, expert testimony, grants or patents received or pending, or royalties.

Peer reviewers on this manuscript have no relevant financial or other relationships to disclose.

Figure 1. VEGFR-2 and VEGF molecular pathways; FGFRs and molecular pathways; PDGFRs and molecular pathways; RET and molecular pathway; c-KIT and molecular pathway.

\section{Bibliography}

\section{Papers of special note have been highlighted as either of interest ( $\bullet$ ) or of considerable interest (••) to readers.}


1 Siegel RL, Miller KD, Jemal A. Cancer statistics, 2018. CA Cancer J Clin 2018; 68: 730 .

2 Siegel RL, Miller KD, Jemal A. Cancer statistics, 2017. CA Cancer J Clin 2017; 67: 730 .

3 Garfield K, LaGrange CA. Cancer, Renal Cell. 2017.

$4 \quad$ Kelsey R. Kidney cancer: Novel drug for renal cell carcinoma. Nat Rev Urol 2016; 13: 6.

5 Choueiri TK, Motzer RJ. Systemic Therapy for Metastatic Renal-Cell Carcinoma. N Engl J Med 2017; 376: 354-366.

6 Matsui J, Yamamoto Y, Funahashi Y, Tsuruoka A, Watanabe T, Wakabayashi T et al. E7080, a novel inhibitor that targets multiple kinases, has potent antitumor activities against stem cell factor producing human small cell lung cancer H146, based on angiogenesis inhibition. Int J Cancer 2008; 122: 664-671.

-First data on the use of lenvatinib n solid tumor

7 Matsui J, Funahashi Y, Uenaka T, Watanabe T, Tsuruoka A, Asada M. Multi-Kinase Inhibitor E7080 Suppresses Lymph Node and Lung Metastases of Human Mammary Breast Tumor MDA-MB-231 via Inhibition of Vascular Endothelial Growth FactorReceptor (VEGF-R) 2 and VEGF-R3 Kinase. Clin Cancer Res 2008; 14: 5459-5465. - First data on the use of lenvatinib $n$ solid tumor

8 Okamoto K, Kodama K, Takase K, Sugi NH, Yamamoto Y, Iwata M et al. Antitumor activities of the targeted multi-tyrosine kinase inhibitor lenvatinib (E7080) against RET gene fusion-driven tumor models. Cancer Lett 2013; 340: 97-103.

- First data on the use of lenvatinib n solid tumor

9 Motzer RJ, Hutson TE, Glen H, Michaelson MD, Molina A, Eisen T et al. Lenvatinib, everolimus, and the combination in patients with metastatic renal cell carcinoma: a randomised, phase 2, open-label, multicentre trial. Lancet Oncol 2015; 16: 1473-82. ••Phase II study who led tot he approvation of lenvatininb+everolimus in RCC

10 Kessler PM, Vasavada SP, Rackley RR, Stackhouse T, Duh FM, Latif F, et al. Expression of the Von Hippel-Lindau tumor suppressor gene, VHL, in human fetal kidney and during mouse embryogenesis. Mol Med 1995;1:457-66.

11 van Houwelingen KP, van Dijk BA, Hulsbergen-van de Kaa CA, Schouten LJ, Gorissen HJ, Schalken JA, et al. Prevalence of von Hippel-Lindau gene mutations in sporadic renal cell carcinoma: results from the Netherlands cohort study. BMC Cancer 2005;5:57

12 Shibuya M. Vascular Endothelial Growth Factor (VEGF) and Its Receptor (VEGFR) Signaling in Angiogenesis: A Crucial Target for Anti- and Pro-Angiogenic Therapies. Genes Cancer 2011; 2: 1097-105. 
13 Muller YA, Li B, Christinger HW, Wells JA, Cunningham BC, de Vos AM. Vascular endothelial growth factor: crystal structure and functional mapping of the kinase domain receptor binding site. Proc Natl Acad Sci U S A 1997; 94: 7192-7.

14 Sawano A, Takahashi T, Yamaguchi S, Aonuma M, Shibuya M. Flt-1 but not KDR/Flk-1 tyrosine kinase is a receptor for placenta growth factor, which is related to vascular endothelial growth factor. Cell Growth Differ 1996; 7: 213-21.

15 Lee JS, Kim HS, Jung JJ, Park CS, Lee MC. Expression of vascular endothelial growth factor in renal cell carcinoma and the relation to angiogenesis and p53 protein expression. J Surg Oncol 2001; 77: 55-60.

16 Song SH, Jeong IG, You D, Hong JH, Hong B, Song C et al. VEGF/VEGFR2 and PDGFB/PDGFR- $\beta$ expression in non-metastatic renal cell carcinoma: a retrospective study in 1,091 consecutive patients. Int J Clin Exp Pathol 2014; 7: 7681-9.

17 Avivi A, Skorecki K, Yayon A, Givol D. Promoter region of the murine fibroblast growth factor receptor 2 (bek/KGFR) gene. Oncogene 1992; 7: 1957-62.

18 Thompson LM, Plummer S, Schalling M, Altherr MR, Gusella JF, Housman DE et al. A gene encoding a fibroblast growth factor receptor isolated from the Huntington disease gene region of human chromosome 4. Genomics 1991; 11: 1133-42.

19 Dieci MV, Arnedos M, Andre F, Soria JC. Fibroblast Growth Factor Receptor Inhibitors as a Cancer Treatment: From a Biologic Rationale to Medical Perspectives. Cancer Discov 2013; 3: 264-279.

20 Helsten T, Elkin S, Arthur E, Tomson BN, Carter J, Kurzrock R. The FGFR Landscape in Cancer: Analysis of 4,853 Tumors by Next-Generation Sequencing. Clin Cancer Res 2016; 22: 259-267.

21 Tsimafeyeu I, Demidov L, Stepanova E, Wynn N, Ta H. Overexpression of fibroblast growth factor receptors FGFR1 and FGFR2 in renal cell carcinoma. Scand J Urol Nephrol 2011; 45: 190-195.

22 Presta M, Dell'Era P, Mitola S, Moroni E, Ronca R, Rusnati M. Fibroblast growth factor/fibroblast growth factor receptor system in angiogenesis. Cytokine Growth Factor Rev 2005;16:159-78.

23 Cao Y, Cao R, Hedlund E-M. R Regulation of tumor angiogenesis and metastasis by FGF and PDGF signaling pathways. J Mol Med 2008;86:785-9.

24 Korc M, Friesel RE. The role of fibroblast growth factors in tumor growth. Curr Cancer Drug Targets 2009;9:639-51.

25 Cho D, Signoretti S, Regan M, Mier JW, Atkins MB. The Role of Mammalian Target of Rapamycin Inhibitors in the Treatment of Advanced Renal Cancer. Clin Cancer Res 2007; 13: 758s-763s. 
26 Tang M, Bian W, Cheng L, Zhang L, Jin R, Wang W et al. Ginsenoside Rg3 inhibits keloid fibroblast proliferation, angiogenesis and collagen synthesis in vitro via the TGF $\beta /$ Smad and ERK signaling pathways. Int J Mol Med 2018; 41: 1487-1499.

27 Matsuki M, Adachi Y, Ozawa Y, et al. Targeting of tumor growth and angiogenesis underlies the enhanced antitumor activity of lenvatinib in combination with everolimus. Cancer Sci. 2017;108(4):763-771.

28 Leonetti A, Leonardi F, Bersanelli M, Buti S. Clinical use of lenvatinib in combination with everolimus for the treatment of advanced renal cell carcinoma. Ther Clin Risk Manag 30 June 2017.

-Review on the use of lenvatinib for $R C C$

29 Boss DS, Glen H, Beijnen JH, et al. A phase I study of E7080, a multitargeted tyrosine kinase inhibitor, in patients with advanced solid tumours. $\mathrm{Br} \mathrm{J}$ Cancer. 2012;106(10):1598-1604.

-First phase I study with lenvatinib

30 Molina AM, Hutson TE, Larkin J, et al. A phase 16 clinical trial of the multi-targeted tyrosine kinase inhibitor lenvatinib (E7080) in combination with everolimus for treatment of metastatic renal cell carcinoma (RCC). Cancer Chemother Pharmacol. 2014;73(1):181-189.

$\bullet$ First exeperience on the combination of lenavatinib+everolimus in RCC

31 Motzer RJ, Hutson TE, Ren M, Dutcus C, Larkin J. Independent assessment of lenvatinib plus everolimus in patients with metastatic renal cell carcinoma. Lancet Oncol. 2016;17(1):e4-e5.

$\bullet$ Post-hoc analysis of first phase II study

32 Long J, Lin J, Wang A, Wu L, Zheng Y, Yang X, et al. PD-1/PD-L blockade in gastrointestinal cancers: lessons learned and the road toward precision immunotherapy. J Hematol Oncol 2017;10:146. doi:10.1186/s13045-017-0511-2.

33 Eisai Presents Data of Mechanisms of Action Relating to Tumor Immune Response Regarding Combination of Anticancer Agent Lenvatinib With Anti-PD-1 Antibody at AACR 108th Annual Meeting n.d. https://www.acnnewswire.com/press-release/english/35857/ (accessed April 12, 2018). 


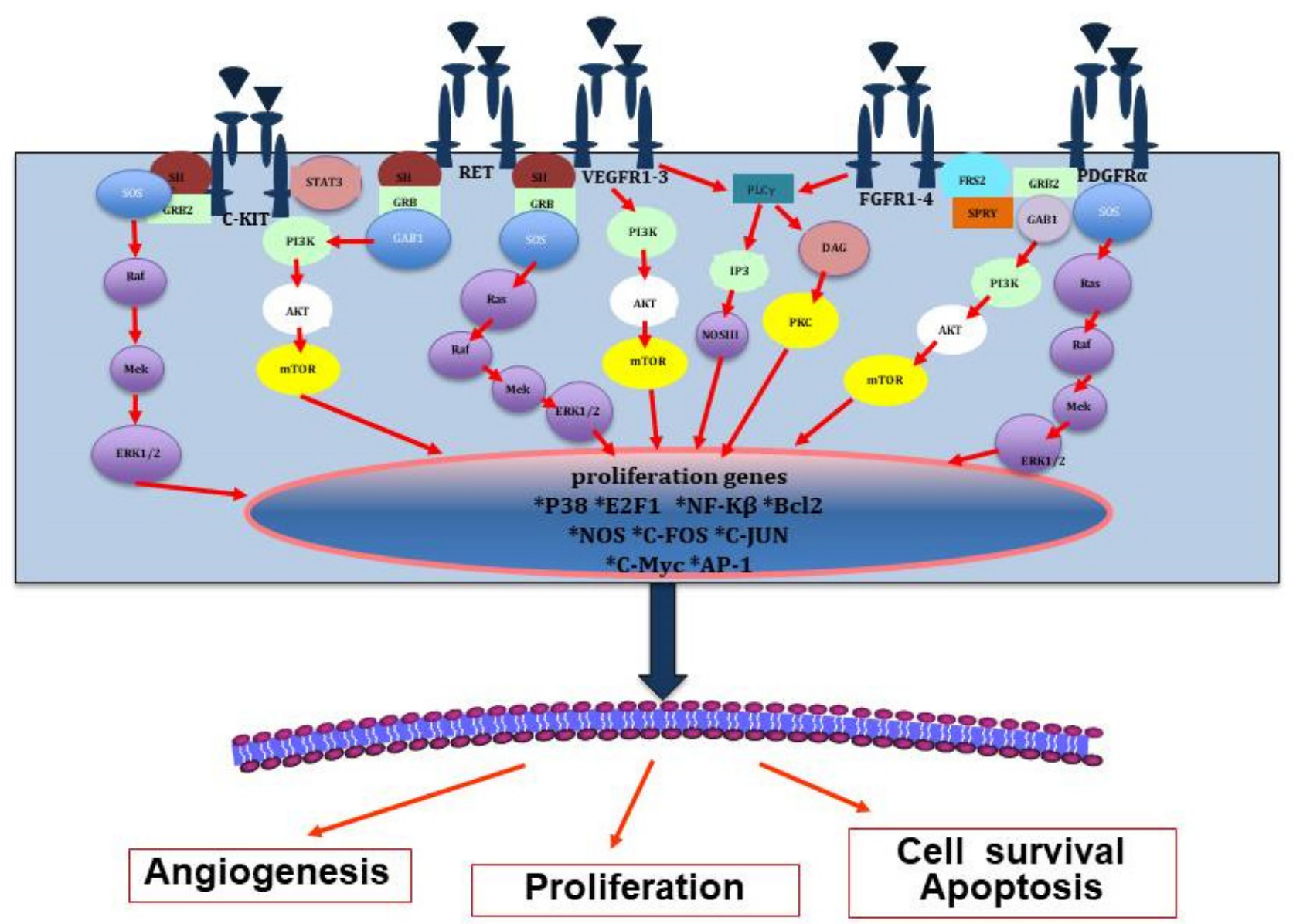


Table 1: Selected ongoing trials with Lenvatinib in renal cell carcinoma.

\begin{tabular}{|c|c|c|c|c|c|c|}
\hline $\begin{array}{l}\text { Clinical trial } \\
\text { identifier }\end{array}$ & $\begin{array}{l}\text { Study De- } \\
\text { sign }\end{array}$ & Intervention/s & Setting & $\begin{array}{l}\text { Primary } \\
\text { endpoint }\end{array}$ & Phase & Status \\
\hline NCT02811861 & $\begin{array}{l}735 \text { patients, } \\
\text { Randomized, } \\
\text { Open label }\end{array}$ & $\begin{array}{l}\text { Lenvatinib + evero- } \\
\text { limus (Arm A: } 18 \mathrm{mg} \\
\text { daily for lenvatinib } \\
\text { and 5mg daily for } \\
\text { everolimus) or Len- } \\
\text { vatinib + pembroli- } \\
\text { zumab (Arm B: } \\
\text { 20mg daily for len- } \\
\text { vatinib plus } 200 \mathrm{mg} \\
\text { pembrolizumab dai- } \\
\text { ly) vs Sunitinib (Arm } \\
\text { C: } 50 \mathrm{mg} \text { daily) }\end{array}$ & First line & PFS & 3 & Recruiting \\
\hline NCT03173560 & $\begin{array}{l}20 \text { partici- } \\
\text { pants, } \\
\text { Randomized, } \\
\text { Parallel as- } \\
\text { signment, } \\
\text { Triple mask- } \\
\text { ing (Partici- } \\
\text { pant, Inves- } \\
\text { tigator, Out- } \\
\text { comes As- } \\
\text { sessor) }\end{array}$ & $\begin{array}{l}\text { Lenvatinib + evero- } \\
\text { limus (Arm A: } 18 \mathrm{mg} \\
\text { daily for lenvatinib } \\
\text { plus } 5 \mathrm{mg} \text { for evero- } \\
\text { limus; Arm B: } 18 \mathrm{mg} \\
\text { daily for lenvatinib } \\
\text { and } 5 \mathrm{mg} \text { daily for } \\
\text { everolimus) }\end{array}$ & $\begin{array}{l}\text { Second } \\
\text { line }\end{array}$ & $\begin{array}{c}\text { ORR, } \\
\text { TEAES }\end{array}$ & 2 & Recruiting \\
\hline NCT03324373 & $\begin{array}{l}13 \text { partici- } \\
\text { pants, Single } \\
\text { group as- } \\
\text { signment, } \\
\text { Open label }\end{array}$ & $\begin{array}{l}\text { Lenvatinib + evero- } \\
\text { limus ( } 18 \mathrm{mg} \text { daily for } \\
\text { lenvatinib plus } 5 \mathrm{mg} \\
\text { daily for everolimus) }\end{array}$ & First line & ORR & 2 & $\begin{array}{l}\text { Not yet } \\
\text { recruiting }\end{array}$ \\
\hline NCT02915783 & $\begin{array}{l}31 \text { partici- } \\
\text { pants, Single } \\
\text { group as- } \\
\text { signment, } \\
\text { Open label }\end{array}$ & $\begin{array}{l}\text { Lenvatinib + evero- } \\
\text { limus ( } 18 \mathrm{mg} \text { daily } \\
\text { for lenvatinib plus } \\
5 \mathrm{mg} \text { daily for evero- } \\
\text { limus) }\end{array}$ & First line & ORR & 2 & Recruiting \\
\hline
\end{tabular}

